\title{
Global effect factors for exposure to fine particulate matter
}

Fantke, Peter; McKone, Thomas E.; Tainio, Marko ; Jolliet, Olivier; Apte, Joshua Schulz; Stylianou, Katerina S.; Illner, Nicole; Marshall, Julian D. ; Choma, Ernani F.; Evans, John S.

\section{Published in:}

Environmental Science and Technology

Link to article, DOI:

10.1021/acs.est.9b01800

Publication date:

2019

Document Version

Publisher's PDF, also known as Version of record

Link back to DTU Orbit

Citation (APA):

Fantke, P., McKone, T. E., Tainio, M., Jolliet, O., Apte, J. S., Stylianou, K. S., Illner, N., Marshall, J. D., Choma, E. F., \& Evans, J. S. (2019). Global effect factors for exposure to fine particulate matter. Environmental Science and Technology, 53(12), 6855-6868. https://doi.org/10.1021/acs.est.9b01800

\section{General rights}

Copyright and moral rights for the publications made accessible in the public portal are retained by the authors and/or other copyright owners and it is a condition of accessing publications that users recognise and abide by the legal requirements associated with these rights.

- Users may download and print one copy of any publication from the public portal for the purpose of private study or research.

- You may not further distribute the material or use it for any profit-making activity or commercial gain

- You may freely distribute the URL identifying the publication in the public portal 


\title{
Global Effect Factors for Exposure to Fine Particulate Matter
}

Peter Fantke, ${ }^{* \dagger \odot}$ Thomas E. McKone, ${ }^{\ddagger}$, Marko Tainio, $^{\|, \perp}$ Olivier Jolliet, ${ }^{\# \odot ~ J o s h u a ~ S . ~ A p t e, ~}{ }^{\nabla} \odot$ Katerina S. Stylianou, ${ }^{\#}$ Nicole Illner, ${ }^{\dagger}$ Julian D. Marshall, ${ }^{\diamond}$ Ernani F. Choma, ${ }^{\bigcirc}$ and John S. Evans ${ }^{\bigcirc}$

${ }^{\dagger}$ Quantitative Sustainability Assessment, Department of Technology, Management and Economics, Technical University of Denmark, Produktionstorvet 424, 2800 Kongens Lyngby, Denmark

${ }^{\ddagger}$ School of Public Health, University of California, Berkeley, California 94720, United States

${ }^{\S}$ Lawrence Berkeley National Laboratory, Berkeley, California 94720, United States

"UKCRC Centre for Diet and Activity Research, University of Cambridge, Cambridge, United Kingdom

${ }^{\perp}$ Systems Research Institute, Polish Academy of Sciences, Warsaw, Poland

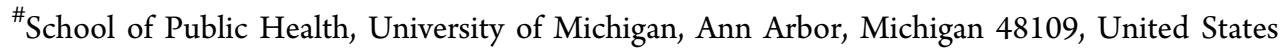

${ }^{\nabla}$ Department of Civil, Architectural and Environmental Engineering, University of Texas at Austin, Austin, Texas 78712, United States

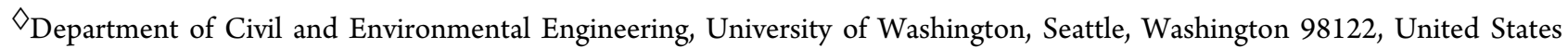

ODepartment of Environmental Health, Harvard Chan School of Public Health, Boston, Massachusetts 02115, United States

\section{Supporting Information}

\begin{abstract}
We evaluate fine particulate matter $\left(\mathrm{PM}_{2.5}\right)$ exposureresponse models to propose a consistent set of global effect factors for product and policy assessments across spatial scales and across urban and rural environments. Relationships among exposure concentrations and $\mathrm{PM}_{2.5}$-attributable health effects largely depend on location, population density, and mortality rates. Existing effect factors build mostly on an essentially linear exposure-response function with coefficients from the American Cancer Society study. In contrast, the Global Burden of Disease analysis offers a nonlinear integrated exposure-response (IER) model with coefficients derived from numerous epidemiological studies covering a wide range of exposure concentrations. We explore the IER, additionally provide a simplified regression as a function of $\mathrm{PM}_{2.5}$ level, mortality rates, and severity, and compare results with effect factors derived from the recently published global exposure mortality model (GEMM). Uncertainty in effect factors is dominated by the exposure-response shape, background mortality, and geographic variability. Our central IER-based effect factor estimates for different regions do not differ substantially from previous estimates. However, IER estimates exhibit significant variability between locations as well as between urban and rural environments, driven primarily by variability in $\mathrm{PM}_{2.5}$ concentrations and mortality rates. Using the IER as the basis for effect factors presents a consistent picture of global $\mathrm{PM}_{2.5}$-related effects for use in product and policy assessment frameworks.

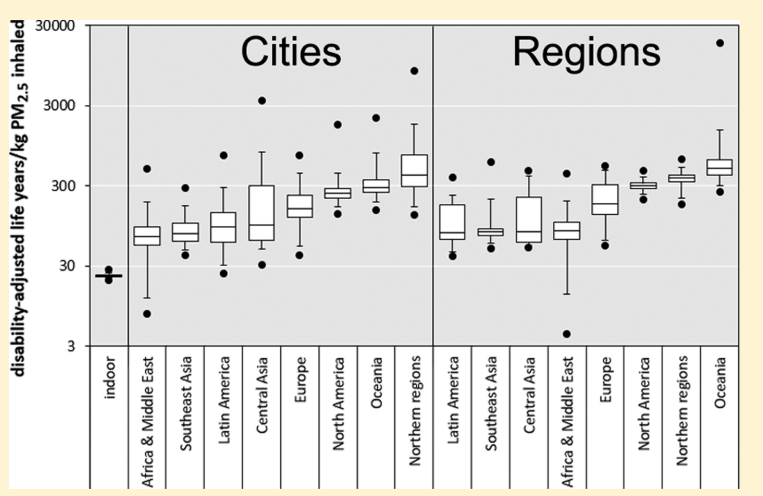

\section{INTRODUCTION}

\subsection{History of Epidemiology-Based Effect Factors.} We evaluate fine particulate matter $\left(\mathrm{PM}_{2.5}\right)$ exposureresponse models to propose a consistent set of global effect factors across spatial scales and across urban and rural environments for use in product and policy assessments, such as life cycle impact assessment (LCIA) and health impact assessment (HIA). Exposure to $\mathrm{PM}_{2.5}$ is the leading environmental contributor to human disease burden, with more than seven million deaths globally attributed to ambient and household $\mathrm{PM}_{2.5}$ exposure in 2015. ${ }^{1}$ The influence of exposure to $\mathrm{PM}_{2.5}$ on mortality rates became clear with the "Harvard Six Cities" study in $1993 .^{2}$ The effect seen was so large that a second, larger, study was conducted involving more than 500000 subjects from 151 communities within the United States. This American Cancer Society (ACS) study, ${ }^{3}$ published in 1995, confirmed the relationship between exposure to $\mathrm{PM}_{2.5}$ and mortality rates for concentrations and composition of $\mathrm{PM}_{2.5}$ in the United States with an effect size roughly one-third as large as that found in the Six Cities study.

Received: March 25, 2019

Revised: $\quad$ May 24, 2019

Accepted: May 27, 2019

Published: May 27, 2019 
At about the same time, Hofstetter ${ }^{4}$ began working on methods for comparing environmental impacts from pollutant emissions along product and service life cycles. As part of this effort, he developed the first approach to address exposure to $\mathrm{PM}_{2.5}$ in large-scale emission-based comparisons. In such comparisons, the most common measure of the relationship between population exposure and health effects is the "effect factor", typically expressed in terms of years of life lost (YLL) or disability-adjusted life years (DALY) for a given population per kilogram intake (e.g., via inhalation) of a pollutant. To be suitable for evaluating different emission situations, such effect factors are combined with human intake fractions relating $\mathrm{PM}_{2.5}$ emissions to population intake. ${ }^{5-7}$ Hofstetter ${ }^{4}$ applied for his effect factor estimates the $\mathrm{PM}_{2.5}$ risk coefficient from the ACS study ( $0.4 \%$ increase in mortality among adults $[\geq 30$ years of age $]$ per $\mu \mathrm{g} / \mathrm{m}^{3}$ ) to cardiopulmonary mortality rates for European adults of 1400 deaths per 100000 person-years. He assumed that the entire effect seen in the ACS study was due to $\mathrm{PM}_{2.5}$ exposure and used a severity factor of 6.6 YLL/ death, deriving effect factors for Europe of 41 YLL per $\mathrm{kg}$ $\mathrm{PM}_{2.5}$ or sulfate inhaled.

Over the past 25 years, the Six Cities and ACS studies have been frequently extended and reanalyzed, ${ }^{8-11}$ and several new cohorts have been evaluated. ${ }^{12-20}$ These studies have repeatedly confirmed that mortality rates are higher at higher levels of $\mathrm{PM}_{2.5}$ exposure-even after accounting (at the individual level) for differences in behavior, socioeconomic status, and other factors known to affect mortality rates. A recent meta-analysis of these studies associated a $1.1 \%$ increase in cardiovascular mortality per $\mu \mathrm{g} / \mathrm{m}^{3}$ increase in $\mathrm{PM}_{2.5}$, with study-to-study results variability thought to be attributable to difference in particle composition, building air exchange rates, demographic factors, and meteorology. ${ }^{21}$

In parallel, several research groups have published new PMrelated effect factors, including estimates yielding $58 \mathrm{YLL}$ per $\mathrm{kg} \mathrm{PM}_{10}$ inhaled in Europe ${ }^{22}$ and 64 YLL (78 DALY) per kg $\mathrm{PM}_{2.5}$ inhaled in the United States. ${ }^{23}$ More recent estimates are more variable and in part substantially larger than previous estimates, ${ }^{24,25}$ with estimates for example ranging for Europe from $192 \mathrm{YLL}$ (France) to $622 \mathrm{YLL}$ (Bulgaria) per kg $\mathrm{PM}_{2.5}$ inhaled and for North America from 151 YLL (Mexico) to 395 YLL (Canada), with the United States at 287 YLL, per $\mathrm{kg}$ $\mathrm{PM}_{2.5}$ inhaled. ${ }^{24}$

All described estimates have relied on risk coefficients from the original ACS study or one of its follow-up studies. Van Zelm et al. $(2008)^{22}$ used a risk coefficient of $0.43 \%(0.26-$ $0.91 \%)$ per $\mu \mathrm{g} / \mathrm{m}^{3} \mathrm{PM}_{10}$ based on Künzli's synthesis of results from the Six Cities and ACS studies. ${ }^{26}$ We note that because the ACS study is much larger than the Six Cities study, Künzli's pooled risk coefficient is very similar to the coefficient from the ACS study. Further, although the original coefficients were applied to $\mathrm{PM}_{2.5}$, in an attempt to be conservative, Künzli et al. ${ }^{26}$ presented these as if they applied to all inhalable particles $\left(\mathrm{PM}_{10}\right)$. Gronlund et al. ${ }^{23}$ used risk coefficients of $0.6 \%(0.2-$ $1 \%)$ and $0.8 \%(0.1-1.6 \%)$ per $\mu \mathrm{g} / \mathrm{m}^{3} \mathrm{PM}_{2.5}$ for, respectively, cardiopulmonary mortality and lung cancer, taken from the 2002 extension of the ACS study. ${ }^{8}$ These were applied to disease-specific background mortality rates in the United States in 1982-88 (640 deaths per 100000 persons and year for cardiopulmonary disease and 82 deaths per 100000 persons and year for lung cancer) combined with severity factors of 13 YLL (17 DALY) per death for cardiopulmonary disease and 27 YLL (28 DALY) per death for lung cancer. Recent studies ${ }^{24,25}$ used $1.3 \%(1.0-1.6 \%)$ and $1.4 \%(0.6-2.3 \%)$ per $\mu \mathrm{g} / \mathrm{m}^{3} \mathrm{PM}_{2.5}$ for, respectively, cardiopulmonary mortality and lung cancer from the 2009 reanalysis of the ACS study, adjusted for ecological covariates. ${ }^{9}$ The underlying risk coefficients are approximately three times larger than those used to support Hofstetter's original estimate of $41 \mathrm{YLL} / \mathrm{kg} \mathrm{PM} \mathrm{PM}_{2.5}$ inhaled. $^{4}$

These studies have attempted to characterize the uncertainty inherent in their results by relying on estimates of the parameter uncertainty in risk coefficients from the underlying epidemiological studies. None of these analyses, however, considered the epistemic uncertainty introduced by using a study conducted in the United States to estimate health impacts from exposure to $\mathrm{PM}_{2.5}$ in other regions. ${ }^{25}$

The original ACS study cohort was exposed to annual average $\mathrm{PM}_{2.5}$ concentrations varying from 9 to $34 \mu \mathrm{g} / \mathrm{m}^{3}$, while worldwide $\mathrm{PM}_{2.5}$ levels vary from $<5$ to $>300 \mu \mathrm{g} / \mathrm{m}^{3}{ }^{27}$ If the true relationship between $\mathrm{PM}_{2.5}$ concentration and mortality is strictly proportional, risk estimates derived using a proportional exposure-response model would be appropriate. However, if the true exposure-response relationship is nonlinear, this approach (i.e., extrapolating globally from U.S. results) is not satisfactory. Furthermore, the ACS study cohort was exposed to $\mathrm{PM}_{2.5}$ with a composition resulting from a specific source mixture and atmospheric conditions in the United States, while worldwide $\mathrm{PM}_{2.5}$ compositions may differ significantly from those in the United States. ${ }^{28}$ However, while assessing and comparing emission scenarios aims at evaluating all possible source types, consistently differentiating various anthropogenic and nonanthropogenic $\mathrm{PM}_{2.5}$ sources would require globally spatialized data that are currently lacking. Finally, the ACS study cohort includes residents with an ethnic mix, health-relevant behaviors (e.g., smoking, diet), socioeconomic status, and access to health care all specific to the United States. However, if the influence of these coexposures or behavioral factors is not multiplicative, then the use of an exposure-response model based on relative risk does not provide a satisfactory approach for decomposing observed mortality into components attributable to exposure to ambient $\mathrm{PM}_{2.5}$ and components attributable to other causal factors.

These issues of synthesizing evidence, shape of exposureresponse, potential differential toxicity, and extrapolation of epidemiological results from the United States and Western Europe to the rest of the world are relevant to various assessment communities but also to regulatory authorities around the world. All of them face the question of how best to synthesize and interpret this large and growing body of evidence on the mortality effects from PM exposure. One synthesis effort of particular interest underlies the Global Burden of Disease (GBD) studies. Since 2010, the GBD has relied on an integrated exposure-response (IER) model to characterize risks from exposure to $\mathrm{PM}_{2.5}{ }^{1,29-31}$ In this effort, (i) a variety of exposure-response functions was explored instead of assuming proportionality, (ii) a counterfactual level of pollution was explicitly accounted for, below which no effect would be seen, (iii) evidence from all major cohort studies of ambient $\mathrm{PM}_{2.5}$ and mortality was synthesized, and (iv) it was assumed that all fine particles were equivalently toxic (per unit mass inhaled), incorporating evidence from studies involving exposure to active and passive cigarette smoke and indoor smoke from cooking and heating using dung and other dirty fuels. $^{32,33}$ The IER approach has been well received and provided the basis for a number of prominent estimates of the global health impact of exposure to $\mathrm{PM}_{2.5} \cdot{ }^{29,34-36}$ 
1.2. Toward Appropriate Global Effect Factor

Estimates. At the 2016 Pellston expert workshop on 'Global Guidance for Life Cycle Impact Assessment Indicators and Methods', ${ }^{37,38}$ an international group of researchers focused on understanding the suitability of the IER approach for developing globally applicable $\mathrm{PM}_{2.5}$ effect factors linking change in mortality to change in exposure. The main goal was to provide $\mathrm{PM}_{2.5}$ effect factors appropriate for different emission situations (unknown location, known continent or subcontinent, known country or subnational region, and urban area emissions with known city). For each situation, we apply the IER from the 2015 GBD study to (i) understand the factors responsible for variation in derived effect factors, (ii) compare these results with previous estimates and with estimates derived using an alternative exposure-response model, and (iii) promote discussion of the importance of approaches for synthesizing evidence and characterizing effect factor uncertainty. Combining our effect factors with intake fractions will allow for a spatialized evaluation of different $\mathrm{PM}_{2.5}$ emission situations suitable for use in LCIA, HIA, other comparative risk and impact assessments, and analyses of emission reduction policies.

\section{MATERIALS AND METHODS}

2.1. General Approach Followed. Our approach for deriving effect factors for exposure to $\mathrm{PM}_{2.5}$ involves the following steps. (1) Synthesis of epidemiological literature is used to provide a risk coefficient, $\beta$ (\% increase in mortality rate per $\mu \mathrm{g} \mathrm{PM}_{2.5} / \mathrm{m}^{3}$ ), or a set of $d$ disease-specific (and, for certain diseases, age-specific) risk coefficients, $\beta_{\mathrm{d}_{1}}, \beta_{\mathrm{d}_{2}}, \ldots, \beta_{\mathrm{d}_{n}}$, reflecting the selected synthesis of exposure-response functions of some arbitrary shape. (2) Estimates of the annual mean $\mathrm{PM}_{2.5}$ exposure concentrations $\left(\mu \mathrm{g} / \mathrm{m}^{3}\right)$ and data on overall mortality, $M$ (deaths/year), in the regions of interest are obtained. (3) Exposure estimates are combined with mortality rates to compute, in each region of interest, the relative risk, $R R$ (dimensionless), corresponding to the ambient $\mathrm{PM}_{2.5}$ exposure concentration level, $C\left(\mu \mathrm{g} / \mathrm{m}^{3}\right)$, the attributable risk fraction, $A R F$ (dimensionless), as the fraction of mortality attributable to exposure to $\mathrm{PM}_{2.5}$, and the related $\mathrm{PM}_{2.5}$-attributable mortality, $M_{\mathrm{PM} 2.5}$ (deaths/year). (4) Estimates of severity, SF (YLL/death or DALY/death), appropriate for each cause of death or disability and region of interest are obtained. (5) The above factors are used to compute the health effects (YLL or DALY) from exposure to $\mathrm{PM}_{2.5}$ in each region of interest as exposure-response factor, $E R F=\mathrm{d} M_{\mathrm{PM} 2.5} / \mathrm{d} C \times S F$. (6) To link health burden to human intake, the change in intake is computed as the product of the change in annual $\mathrm{PM}_{2.5}$ concentration, $\Delta C\left(\mu \mathrm{g} / \mathrm{m}^{3}\right)$, a nominal breathing rate, $B R\left(\mathrm{~m}^{3} /\right.$ person $\left./ \mathrm{d}\right)$, and the population count in each region of interest, $N_{\text {pop }}$ (persons). After converting micrograms to kilograms and days to year, we yield a dose$\mathrm{res} \mathrm{p}$ o n s e

$D R F=E R F /\left(N_{\text {pop }} \times B R \times 10^{9 \mu \mathrm{g}} \frac{\mathrm{kg}}{\mathrm{kg}} \times 365 \frac{\mathrm{d}}{\text { year }}\right) . \quad$ (7) Effect factors, EF (YLL or DALY per kg $\mathrm{PM}_{2.5}$ inhaled), are finally calculated and defined as the slope of the relationship between effects and inhalation exposure. This process provides additional health burden attributable to $\mathrm{PM}_{2.5}$ exposure, $\Delta M_{\mathrm{PM} 2.5}$ (deaths/year), per increment of increased intake of $\mathrm{PM}_{2.5}, \Delta I$ ( $\mathrm{kg}$ inhaled/year), by the exposed population in each region of interest.
Following this approach, our analysis relies on the IER model from the 2015 GBD study and uses data for $\mathrm{PM}_{2.5}$ exposure concentration, mortality, severity, population count, and breathing rates as detailed in the following.

2.2. Synthesis of Epidemiological Evidence. There have been several attempts to synthesize evidence from existing epidemiological studies but none as ambitious as the GBD's IER. On the assumption of the equitoxicity of $\mathrm{PM}_{2.5}$ (i.e., assuming particles are equivalently toxic per unit mass inhaled), ${ }^{1}$ the IER considers evidence not only from epidemiological studies of ambient $\mathrm{PM}_{2.5}$ but also from epidemiological studies examining the impact of exposure to indoor smoke and from exposure to both active and passive cigarette smoke. ${ }^{32,33}$ The general form of the GBD's IER relative risk $(R R)$ models is:

$$
R R(C)=\left\{\begin{array}{cc}
1+\alpha \times\left(1-\mathrm{e}^{-\beta \times\left(C-C_{0}\right)^{\delta}}\right) & \text { for } C \geq C_{0} \\
1 & \text { for } C<C_{0}
\end{array}\right.
$$

with $C$ being the $\mathrm{PM}_{2.5}$ exposure concentration, $C_{0}$ the theoretical minimum risk exposure level (TMREL; also referred to as "counterfactual"), $1+\alpha$ the maximum relative risk, $\beta$ the ratio of relative risk at low-to-high $\mathrm{PM}_{2.5}$ exposure, and $\delta$ the power of $\mathrm{PM}_{2.5}$ exposure concentration.

The 2010 GBD study was the first major application of the IER model. ${ }^{29}$ This model is well known, has been widely used, and has been refitted twice, incorporating additional epidemiological studies and using somewhat different statistical methods. The 2013 coefficients $^{32}$ have been used extensively. ${ }^{34,35}$ The most recent update produced the 2015 coefficients that provided the basis for a study reviewing 25 years of mortality attributable to $\mathrm{PM}_{2.5}$ exposure. ${ }^{36}$ The IER model is applied separately to each of five causes of death: ischemic heart disease (IHD), stroke, chronic obstructive pulmonary disease (COPD), and lung cancer in adults, as well as acute lower respiratory infections (ALRI) in children. For IHD and stroke, the IER model is applied separately to each of 12 age groups: $25-29$ years, ..., $75-79$ years, and $\geq 80$ years. For COPD and lung cancer, IER model parameters are estimated only once and they apply to all individuals over 25 years of age. For ALRI, the model is applied to children below 5 years of age.

The IER model used in the GBD study ${ }^{32}$ accounts for uncertainty by providing 1000 equally likely sets of values for the model coefficients $\alpha, \beta, \delta$, and $C_{0}$ for each disease and age group of interest. These sets of coefficients are generated by creating 1000 equally likely data sets and then determining the values of $\alpha, \beta, \delta$, and $C_{0}$, with a mean $C_{0}=4.2 \mu \mathrm{g} / \mathrm{m}^{3}$. Individual data sets are generated by drawing one set of values of relative risk and $\mathrm{PM}_{2.5}$ exposure concentration for each cohort study under consideration from a pool of relative risk and $\mathrm{PM}_{2.5}$ exposure concentration values thought to represent the study.

Strengths of the GBD's IER model include the following: ${ }^{36}$ (i) It reflects virtually all available published cohort studies of mortality attributable to $\mathrm{PM}_{2.5}$ exposure. (ii) It begins with a highly flexible set of exposure-response functions and objective criteria to select among them. (iii) It uses sophisticated statistical methods to account for betweenstudy heterogeneity. (iv) It provides users with an approach for characterizing parameter uncertainty. (v) It includes input from a large group of leading experts in the field of $\mathrm{PM}_{2.5}$ 
epidemiology. (vi) It is published in the peer-reviewed literature, widely used, and updated frequently. (vii) It covers the entire range of $\mathrm{PM}_{2.5}$ exposure concentrations of interest by incorporating evidence from studies of ambient $\mathrm{PM}_{2.5}$, indoor $\mathrm{PM}_{2.5}$ from cook stoves and passive smoking, along with data on $\mathrm{PM}_{2.5}$ exposures and risks among active smokers.

Potential limitations of the GBD's IER model include the following: (i) The effect of including epidemiological evidence from studies of direct smoking is to flatten the exposureresponse function at high concentrations, which is especially relevant for populations exposed to highly polluted ambient air (e.g., urban China, India). (ii) A secondary effect of including evidence from direct smoking is that reported uncertainty in estimates of the slope decreases as the concentration increases, with the result that for regions with highly polluted ambient air the IER suggests that the slope is known quite precisely, whereas in fact there is the least direct evidence. (iii) The IER model provides no information about model uncertainty introduced by fundamental lack of scientific understanding of issues necessary to interpret the results as causal or to apply risk estimates to populations that have not been studied epidemiologically or which are exposed to PM with different composition or particle size than those seen in the considered epidemiological studies. (iv) The validity of the IER model, hence, depends on two strong assumptions. The first assumption is that $\mathrm{PM}_{2.5}$ toxicity does not depend on source or chemical composition, since despite substantial efforts neither epidemiological nor toxicological research has conclusively identified particular sources or components that uniquely determine the toxicity of $\mathrm{PM}_{2.5}{ }^{36}$ When used to evaluate emissions, the second assumption is that the exposure concentration needed for the IER model can be obtained from the total inhaled $\mathrm{PM}_{2.5}$ mass per unit emission provided by the intake fraction.

2.3. Model Input Data. 2.3.1. Spatial Resolution of the Analysis. Our analysis considers 175 countries, 18 of which were further divided into subnational regions. The United States was divided into 51 regions (50 states and American Samoa). India was divided into 64 regions (32 urban and 32 rural). China was divided into its 34 provinces, Mexico into 32 states, Brazil into 26 states, Saudi Arabia into 13 provinces, and the UK into 13 counties. In addition, several countries (including Australia, Canada, Gabon, Indonesia, Kenya, Norway, Somalia, Spain, and Uganda) were divided into two and Russia into three regions located in different subcontinents. This yields 419 regions studied. ${ }^{39,40}$ When aggregating regional and national results to the level of 8 continents and 16 subcontinents, we grouped Africa and the Middle East as one continent, Latin America and the Caribbean as one continent, and identify the northern regions of North America, Europe, and Central Asia as a distinct continental region. ${ }^{40}$ In addition, we considered 3448 cities (i.e., urbanized areas with more than 100000 inhabitants). ${ }^{41}$ Following these spatial resolutions renders our resulting effect factors consistent with related intake fraction estimates. ${ }^{39}$

2.3.2. Fine Particulate Matter Exposure Levels. We obtained consistent estimates of the 2016 annual average concentrations of $\mathrm{PM}_{2.5}$ prevalent in each of the 419 regions and 3448 cities considered in our analysis from the World Health Organization. ${ }^{27,42} \mathrm{PM}_{2.5}$ exposure levels used in support of national (or subnational) effect factors reflect population-weighted averages of outdoor $\mathrm{PM}_{2.5}$ concentrations across rural and urbanized areas within each region. $\mathrm{PM}_{2.5}$ exposure levels used in support of city-specific effect factors reflect population-weighted averages of outdoor $\mathrm{PM}_{2.5}$ concentrations in each respective urban area. For comparing cities or regions, the provided resolution in $\mathrm{PM}_{2.5}$ concentrations is sufficient, while higher resolutions would be required for evaluating sources within a given city. Effect factors for ambient environments include exposures both indoors and outdoors (i.e., without a signification contribution from indoor sources). We derive additional effect factors intended for application to situations, where indoor sources constitute a substantial contribution to $\mathrm{PM}_{2.5}$ exposure. We use archetypal levels to characterize environments with significant indoor emissions, for example, related to cook stoves, applying an average indoor $\mathrm{PM}_{2.5}$ concentration of $250 \mu \mathrm{g} / \mathrm{m}^{3}$ as representative of such environments. ${ }^{43,44}$ Since indoor emissions can vary among countries and households as a function of sources and renewal rates, additional scenarios can be evaluated following our general approach for deriving effect factors.

2.3.3. Mortality Data. Estimates of age- and disease-specific mortality, $M$ (deaths/year), for each of the five target health outcomes included in the IER (i.e., IHD, stroke, COPD, lung cancer, and ALRI) in each of the 419 regions of interest for the year 2015 were obtained from the GBD Collaborative Network. ${ }^{45}$ For IHD and stroke, we obtained specific data for each of 12 age groups $(25-29, \ldots, 75-79$, and $\geq 80$ years). For COPD and lung cancer, we obtained data for adult mortality (age $\geq 25$ years). For ALRI, we used data on mortality of infants and very young children (age $\leq 5$ years). Mortality data are available for countries or subnational regions and are applied additionally to all cities in their respective regions.

2.3.4. Attributable Risk Fraction and Deaths Attributable to $P M_{2.5}$ Exposure. Multiplying the attributable risk fraction, $A R F$ (dimensionless), by the current overall mortality, $M$ (death/year), in any given region provided us the mortality (i.e., number of deaths) attributable to $\mathrm{PM}_{2.5}$ exposure, $M_{\mathrm{PM} 2.5}$ (deaths/year), in that region, i.e., $M_{\mathrm{PM} 2.5}=A R F \times M$. For the case of ambient air pollution, in which the entire population is exposed, the attributable risk fraction is a simple function of the relative risk, i.e., $A R F=(R R-1) / R R$.

2.3.5. Severity Factors. Estimates of disease- and regionspecific severity factors for mortality, $S F_{\mathrm{YLL}}$ (YLL/death), and for morbidity and mortality combined, $S F_{\mathrm{DALY}}$ (DALY/death), for the year 2015 were obtained from the GBD Collaborative Network. ${ }^{45}$ Severity varies up to a factor of 5 , mainly due to regional differences in life expectancy. ${ }^{46}$ In the calculation of YLL, the GBD has relied since 2015 on a reference life table constructed using the lowest age-specific mortality rates seen in 2013 in any population larger than 5 million capita. ${ }^{46}$

2.3.6. Exposed Population and Breathing Rate. To compare emission scenarios we relate emission mass to exposure in order to apply effect factors using available intake fraction methods as well as population and breathing rate data. ${ }^{39}$ We obtained population counts across all ages, $N_{\text {pop }}$ (capita), for 3448 cities $^{41}$ and for 419 regions of interest for the year 2015 . $^{45}$ Population counts were summed to city and region definitions. To assess intake, we used a nominal population-average breathing rate of $B R=11.68 \mathrm{~m}^{3} /$ person/ $\mathrm{d},{ }^{39,44}$ accounting for time fractions spent and activity indoors and outdoors, ${ }^{44,47}$ and the equilibrium fraction of ambient particles penetrating indoors. ${ }^{39}$ Due to missing global spatialized data, we assumed an equal distribution of time 
Table 1. Global and (Sub-)continental Effect Factor (DALY/kg $\mathbf{P M}_{2.5}$ inhaled) Mean Values and Lower and Upper 95\% Confidence Interval Limits (values in parentheses)

\begin{tabular}{|c|c|c|c|c|}
\hline \multirow[b]{2}{*}{ region } & \multicolumn{2}{|c|}{ marginal slope } & \multicolumn{2}{|c|}{ average slope } \\
\hline & regions & cities & regions & cities \\
\hline global average & $44(17-127)$ & $54(35-124)$ & $115(49-355)$ & $137(55-1034)$ \\
\hline \multicolumn{5}{|l|}{ continental regions } \\
\hline North America & $115(91-141)$ & $103(70-173)$ & $302(238-384)$ & $259(167-431)$ \\
\hline Latin America & $44(18-80)$ & $42(12-107)$ & $116(45-229)$ & $111(31-283)$ \\
\hline Europe & $74(23-141)$ & $72(22-149)$ & $217(63-465)$ & $190(53-437)$ \\
\hline Africa and Middle East & $43(4-106)$ & $31(3-81)$ & $92(13-195)$ & $77(12-190)$ \\
\hline Central Asia & $49(17-129)$ & $60(15-236)$ & $138(54-395)$ & $201(49-788)$ \\
\hline Southeast Asia & $33(21-77)$ & $32(13-65)$ & $92(58-207)$ & $87(48-168)$ \\
\hline Northern regions & $123(84-165)$ & $187(67-475)$ & $366(213-510)$ & $584(163-1754)$ \\
\hline Oceania & $178(116-297)$ & $112(77-195)$ & $638(301-1511)$ & $332(192-762)$ \\
\hline \multicolumn{5}{|l|}{ subcontinental regions } \\
\hline Central Asia & $49(17-127)$ & $66(15-270)$ & $136(54-388)$ & $188(49-818)$ \\
\hline Indochina & $48(29-79)$ & $41(25-76)$ & $127(78-218)$ & $107(64-187)$ \\
\hline Northern Australia & $177(115-293)$ & $110(79-156)$ & $709(297-1418)$ & $312(202-527)$ \\
\hline Southern Australia and New Zealand & $176(115-293)$ & $112(75-197)$ & $678(290-1361)$ & $349(191-791)$ \\
\hline Southern Africa & $56(27-94)$ & $38(23-67)$ & $114(69-194)$ & $92(60-154)$ \\
\hline North, West, East, and Central Africa & $37(3-133)$ & $28(3-97)$ & $84(14-222)$ & $71(12-184)$ \\
\hline Argentina+ & $48(23-120)$ & $43(19-60)$ & $133(62-317)$ & $112(48-165)$ \\
\hline Brazil+ & $60(18-81)$ & $56(10-117)$ & $164(44-231)$ & $148(27-337)$ \\
\hline Central America+ and Caribbean & $30(17-75)$ & $25(15-57)$ & $78(47-182)$ & $69(43-150)$ \\
\hline United States and Southern Canada & $115(92-139)$ & $100(69-160)$ & $301(237-384)$ & $255(164-459)$ \\
\hline Northern Europe and Northern Canada & $125(88-164)$ & $194(65-554)$ & $374(232-495)$ & $595(166-1681)$ \\
\hline Europe & $75(24-141)$ & $72(20-148)$ & $205(62-450)$ & $190(48-433)$ \\
\hline East Indies and Pacific & $85(68-193)$ & $62(47-98)$ & $219(179-421)$ & $173(126-284)$ \\
\hline India+ & $28(20-41)$ & $29(12-56)$ & $80(61-99)$ & $82(45-136)$ \\
\hline Eastern China & $26(21-32)$ & $27(18-45)$ & $72(58-85)$ & $73(53-108)$ \\
\hline Japan and Korean peninsula & $57(25-79)$ & $44(21-67)$ & $142(59-202)$ & $107(48-170)$ \\
\hline
\end{tabular}

spent indoors/outdoors across cities and regions. This approach leads to a value lower than the breathing rates typically used in the intake fraction literature. However, to facilitate comparison with previous estimates, our effect factors can easily be rescaled. When combining effect factors with intake fractions, which also include information on time spent indoors/outdoors and on breathing rates, the same values for these aspects should be used in both and finally cancel out.

2.4. Approaches for Deriving the Effect Factor Slope. As effect factors reflect health impacts attributable to a unit change in $\mathrm{PM}_{2.5}$ intake, they are obtained as the slope of the relationship between mortality and mass of $\mathrm{PM}_{2.5}$ inhaled. When studying the environmental performance of product or service systems, different slopes are relevant for addressing different perspectives. Consequential studies assess environmental impacts expected in consequence of choosing one studied system over another. This perspective requires "marginal" effect factor slopes. In contrast, attributional studies assess environmental impacts along one life cycle of a given system and require using "average" effect factor slopes. For a linear exposure-response function, marginal and average slopes are identical. However, for nonlinear functions, such as GBD's IER, marginal and average slopes differ. Different effect factors are therefore needed for consequential and attributional studies. Hence, we provide marginal effect factors $E F^{\text {marginal }}$ at a given region or city exposure working point $(C$, $\left.\mu \mathrm{g} / \mathrm{m}^{3}\right)$ and average effect factors $E F^{\text {average }}$ between a given region or city exposure working point $\left(C, \mu \mathrm{g} / \mathrm{m}^{3}\right)$ and the theoretical minimum risk exposure level $\left(C_{0}, \mu \mathrm{g} / \mathrm{m}^{3}\right)$. Both types of effect factors are calculated as a function of the difference in mortality attributable to $\mathrm{PM}_{2.5}$ exposure, $M_{\mathrm{PM} 2.5}$ (deaths/year), divided by the difference in intake, $I$ (kg/year)

$$
E F^{\text {marginal }}\left(C_{j}\right)=\frac{\mathrm{d} M_{\mathrm{PM} 2.5, j}}{\mathrm{~d} I_{j}} \times S F_{i, r}=\frac{\sum_{i, j}\left[\left(R R_{i}\left(C_{j}+\Delta C_{j}\right)-R R_{i}\left(C_{j}\right)\right) \times \frac{M_{i, r}}{R R_{i}\left(C_{r}\right) \times N_{\text {po }, r}} \times S F_{i, r}\right]}{\Delta C_{j} \times B R \times f_{\text {d to yr }} \times f_{\text {kg topg }}}
$$

$$
E F^{\text {average }}\left(C_{j}\right)=\frac{M_{\mathrm{PM} 2.5}\left(C_{j}\right)-M_{\mathrm{PM} 2.5}\left(C_{0}\right)}{I\left(C_{j}\right)-I\left(C_{0}\right)} \times S F_{i, r}=\frac{\sum_{i, j}\left[\left(R R_{i}\left(C_{j}\right)-1\right) \times \frac{M_{i, r}}{R R_{i}\left(C_{r}\right) \times N_{\mathrm{pop}, r}} \times S F_{i, r}\right]}{\left(C_{j}-C_{0}\right) \times B R \times f_{\text {d to yr }} \times f_{\text {kg topg }}}
$$




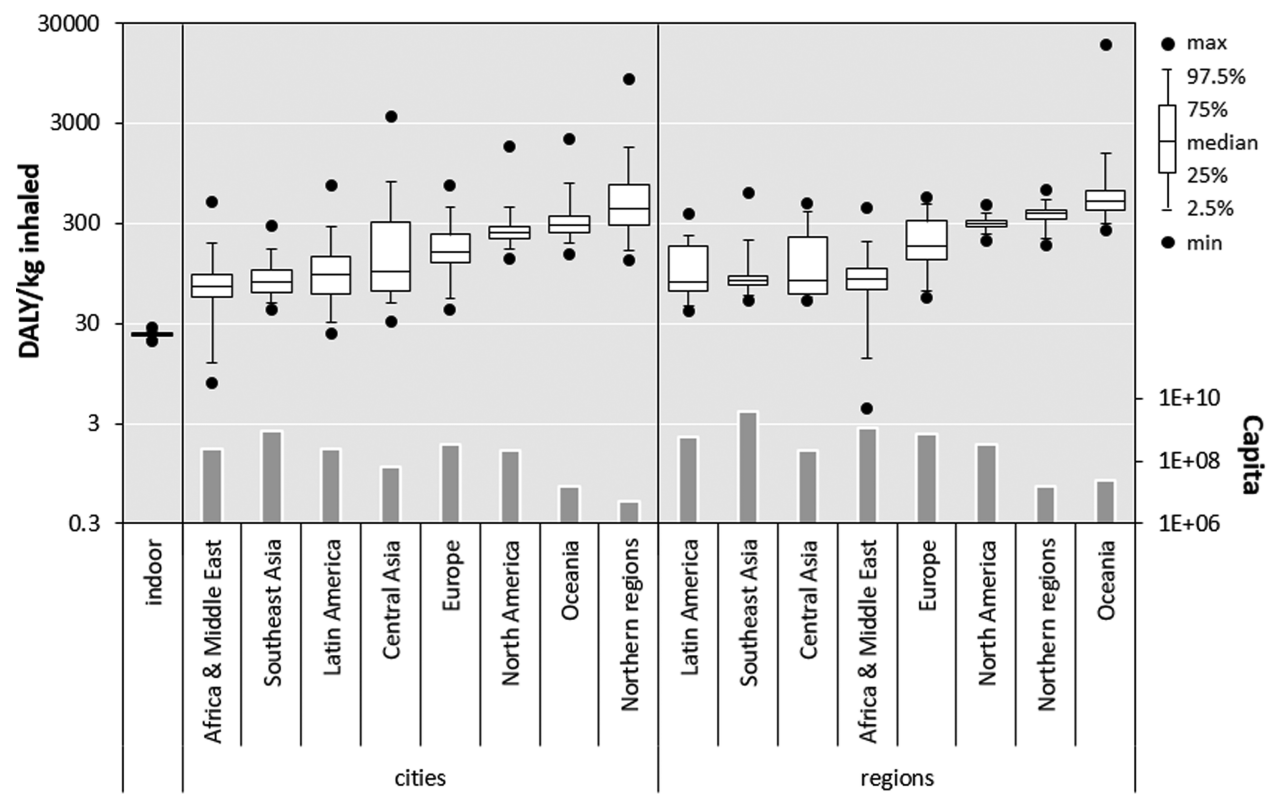

Figure 1. Population-weighted distribution of average effect factors due to $\mathrm{PM}_{2.5}$ exposure across cities (urbanized areas) and regions (including all rural and urban areas within a region) per continent, with a comparison to the average effect factor appropriate for scenarios with substantial emissions from indoor sources. Boxes represent median and interquartile ranges, and whiskers represent ranges containing $95 \%$ of continentspecific effect factors. Continents are arranged from left-to-right in order of increasing mean effect factors. Bars represent total population count (capita) in each continental region and across cities per region.

Equations $2 \mathrm{a}$ and $2 \mathrm{~b}$ are derived from substituting the relative risk in the relation of $\mathrm{PM}_{2.5}$-attributable mortality (see section 2.3.4) and $\mathrm{PM}_{2.5}$ exposure levels as described in section 2.1. More specifically, $R R_{i}\left(C_{j}\right)$ is the relative risk obtained from eq 1 for disease $i$ at the $\mathrm{PM}_{2.5}$ exposure level $C_{j}$ in $j$ th city (for urban effect factors) or in region $j=r$ (for regional effect factors). $M_{i, r}$ is the overall mortality in region $r$ for disease $i$, which contains the city of interest and all other cities and rural areas in a given region. $S F_{i, r}$ is the corresponding region- and disease-specific severity factor. $N_{\text {pop }}$ is the exposed population and $B R$ the individual breathing rate. Units are corrected via factors $f_{\mathrm{d} \text { to yr }}=365 \mathrm{~d} /$ year and $f_{\mathrm{kg} \text { to } \mu \mathrm{g}}=10^{9} \mu \mathrm{g} / \mathrm{kg}$. Ratio $\left(M_{i, r}\right) /\left(R R_{i}\left(C_{r}\right) \times N_{\text {pop }, r}\right)$ is the regional background mortality rate without the influence of $\mathrm{PM}_{2.5}$ exposure, calculated based on the corresponding $\mathrm{PM}_{2.5}$ concentration of that region (i.e., $\left.C_{r}\right)$. If this ratio is multiplied by $\left(R R_{i}\left(C_{r}\right)-1\right)$ in eq $2 \mathrm{~b}$, we get the attributable mortality rate due to $\mathrm{PM}_{2.5}$ exposure. We finally divide by inhaled $\mathrm{PM}_{2.5}$ mass per person (deaths $/ \mathrm{kg}$ inhaled) and multiply by the severity (DALY/death) to yield the effect factor (DALY $/ \mathrm{kg}$ inhaled).

2.5. Implementation and Model Evaluation. We implemented both the marginal and the average approaches in Analytica Release 4.6 and in Microsoft Excel 2016 to derive effect factors for the considered 419 regions and 3448 cities. Results from the two implementations were compared as a quality control measure. All simulations were run using the full set of 1000 equally likely realizations of relative risk model parameters, and uncertainty ranges around effect factors are based on Monte Carlo simulations performed in Analytica.

To evaluate our effect factor estimates we followed two distinct approaches. First, we simplified the effect factor model in a regression, focusing on understanding the most relevant aspects influencing variability in effect factors. This yields additional insight in aspects contributing to linking health effects to human intake and provides a simple tool for practitioners to estimate effect factors based on only knowing the most relevant key inputs, namely, $\mathrm{PM}_{2.5}$ concentration, mortality rates, and disease severity. Second, we compare our effect factors against recent spatialized factors and against factors obtained following our proposed approach but using another exposure-response relationship, namely, the recently published Global Exposure Mortality Model (GEMM), ${ }^{48}$ synthesizing epidemiological evidence from cohorts in 16 countries. Unlike GBD's IER, GEMM exclusively considers studies on ambient $\mathrm{PM}_{2.5}$ exposure.

\section{RESULTS}

3.1. Effect Factors for Total Mortality for Different Levels of Spatial Aggregation. We summarize our results starting with the most general case in which the location of the $\mathrm{PM}_{2.5}$ emission source is unknown (Table 1). In this case, our central effect factor estimates, EF (DALY/ $\mathrm{kg} \mathrm{PM}_{2.5}$ inhaled), reflect the population-weighted (as surrogate for emissionweighted) average of the marginal and average slopes for morbidity and mortality attributable to $\mathrm{PM}_{2.5}$ exposure. When there is no information about emission location, geographic variability contributes significantly to overall effect factor uncertainty. We characterize uncertainty by providing confidence intervals as well as expected values obtained from the distributions of possible values.

Effect factors based on the average slope of the exposureresponse function between the exposure working point and the theoretical minimum risk exposure level tend to be $\sim 2.5$ times larger than effect factors based on the marginal slope of the exposure-response function evaluated at the exposure working point. The mean marginal slope effect factor averaged over the 419 considered regions is $44 \mathrm{DALY} / \mathrm{kg} \mathrm{PM}_{2.5}$ inhaled, with $95 \%$ of region-specific values falling in the range from 17 to $127 \mathrm{DALY} / \mathrm{kg} \mathrm{PM}_{2.5}$ inhaled. In contrast, the mean average slope effect factor averaged over the same 419 regions is 115 $\mathrm{DALY} / \mathrm{kg} \mathrm{PM}_{2.5}$ inhaled, with $95 \%$ of region-specific values falling in the range from 49 to $355 \mathrm{DALY} / \mathrm{kg} \mathrm{PM}_{2.5}$ inhaled. 

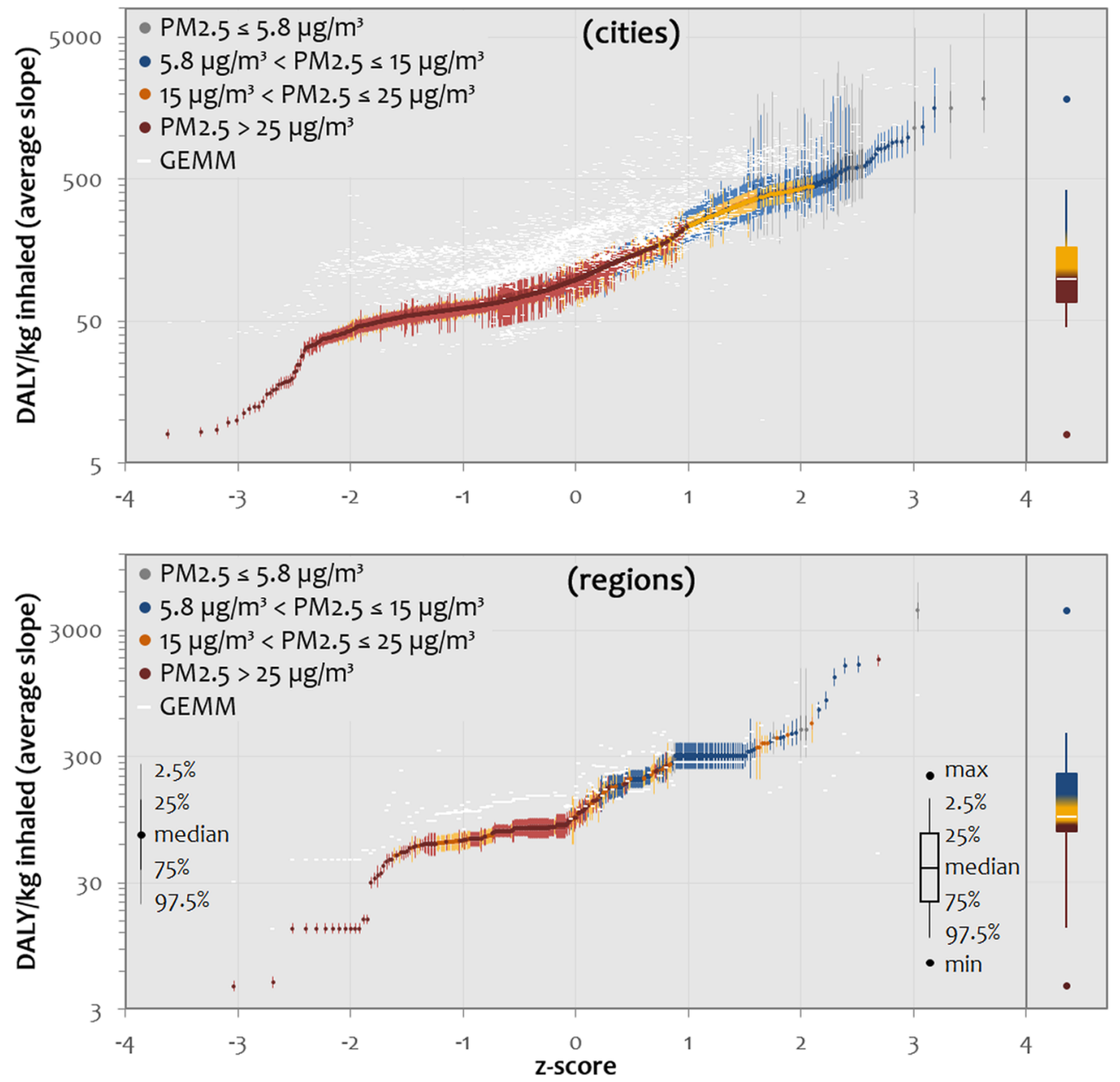

Figure 2. Median effect factor estimates for $\mathrm{PM}_{2.5}$ exposure in 3448 cities (top) and in 419 regions (bottom) with $95 \%$ confidence intervals for each city and region and with the distribution across all cities (top) and across all regions (bottom) indicated as right-side box plots. $z$-scores indicate how many standard deviations city-/region-specific median effect factors are from the respective mean across all considered cities/regions. Median effect factors based on $\mathrm{GEMM}^{48}$ are indicated as white dashes for comparison. Light-colored bars around median values indicate confidence interval ranges.

The mean marginal slope effect factor averaged over the 3448 considered cities is $54 \mathrm{DALY} / \mathrm{kg} \mathrm{PM}_{2.5}$ inhaled, with $95 \%$ of city-specific values falling in the range from 35 to 124 DALY/ $\mathrm{kg} \mathrm{PM}_{2.5}$ inhaled. In contrast, the mean average slope effect factor averaged over these same 3448 cities is $137 \mathrm{DALY} / \mathrm{kg}$ $\mathrm{PM}_{2.5}$ inhaled, with $95 \%$ of region-specific values in the range from 55 to $>1000 \mathrm{DALY} / \mathrm{kg} \mathrm{PM}_{2.5}$ inhaled. Typical city effect factors appear to be slightly (20-30\%) larger than effect factors for regions with a wider variability across cities.

We next consider the case in which the location of $\mathrm{PM}_{2.5}$ emissions is relatively well known, where we can identify either the city or the country (or subnational region) in which a $\mathrm{PM}_{2.5}$ source of interest is located. Marginal and average slope effect factors for all 419 regions and 3448 cities are provided in the Supporting Information (SI).

To provide factors for an intermediate level of spatial detail, between unknown source location and rather precise source specification, we developed and summarize in Figure 1 the average effect factors for regions and cities, aggregated at the level of continents. We estimated the continental weighted median effect factors by pooling the effect factors for each region or city using weights representing the fraction of the population of the continent contributed by each region or city. The continental median as well as the $2.5 \%$ and $97.5 \%$ cumulative probability values come from the distribution $\left(p_{1} \times\right.$ $\left.E F_{1}+p_{2} \times E F_{2}+\ldots+p_{m} \times E F_{m}\right)$, where $p_{1}, p_{2}, \ldots, p_{m}$ are probabilistic weights (Bernoulli variables) taking the value 1 with probability $p$ and 0 with probability $1-p$, and $E F_{1}, E F_{2}$, ..., $E F_{m}$ are probabilistic characterizations of the effect factors from each region or city within a given continent. Marginal and average slope effect factors for (sub)continents are provided in Table 1.

Figure 1 shows average effect factor estimates across regions and urban areas per continent, respectively. In addition, Figure 1 shows the distribution of the average effect factor for the indoor environment archetype with substantial indoor emission sources. For indoor environments, the effect factor based on the average slope between the exposure working point and the theoretical minimum risk exposure level is recommended, since indoor exposure reduction efforts will usually lead to a substantial (nonmarginal) change in indoor $\mathrm{PM}_{2.5}$ concentrations. ${ }^{49}$

Effect factors tend to be higher for exposure levels in North America, Oceania, and Northern Regions than for exposure levels in Southeast Asia, Africa, and the Middle East, Latin America, and Central Asia. Effect factors in Europe tend to fall between these. While there are differences in the typical effect factor by continent, the within-continent variation tends to be 


\section{average EF [DALY/kg inhaled]}
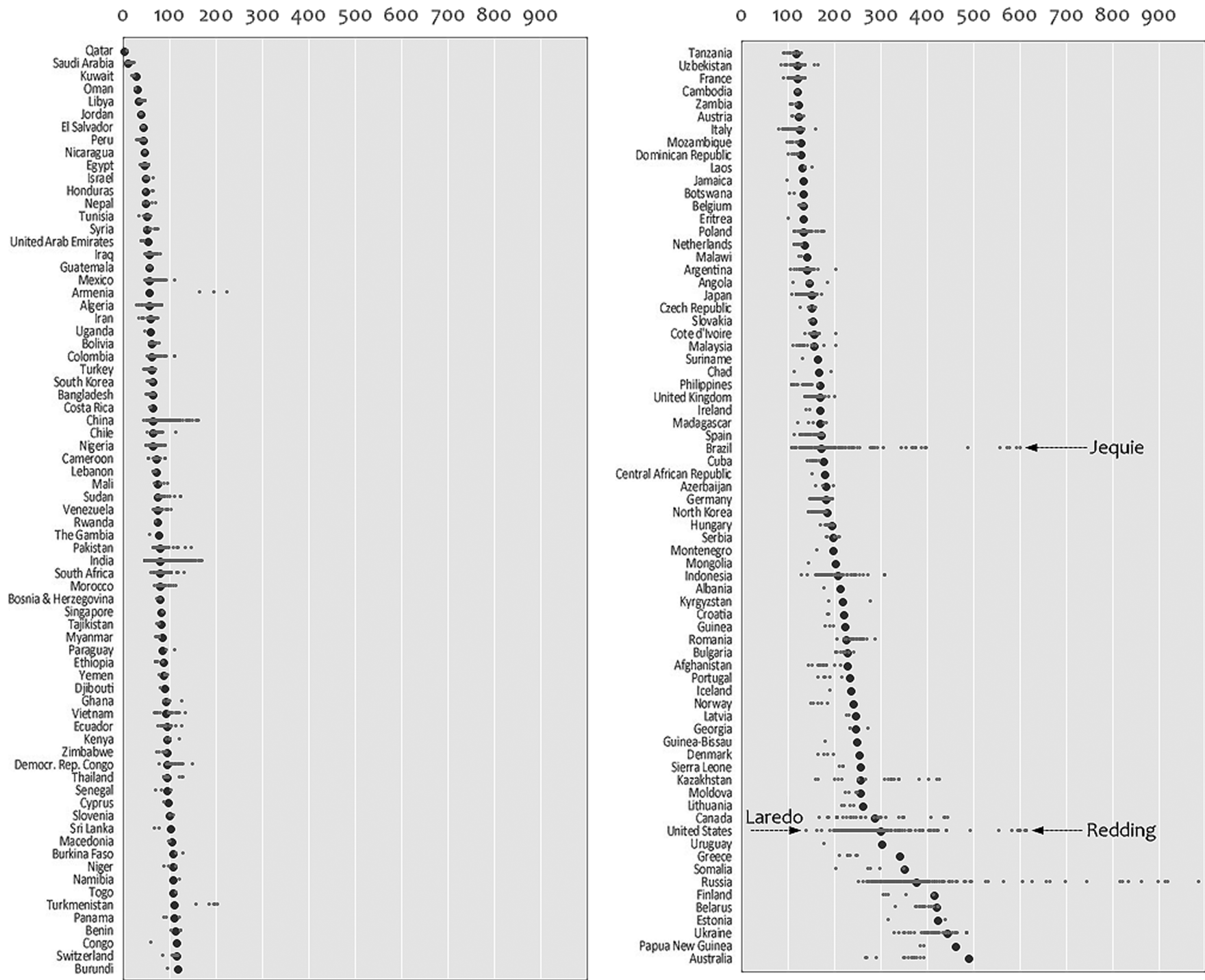

Figure 3. Distribution of average slope median effect factors across cities per country ranked according to increasing country-specific average effect factors that include all rural and urban areas for 147 countries with at least one city with more than 100000 inhabitants.

larger than differences between values typical for various continents.

Indoor effect factors are lower than outdoor effect factors primarily due to the high working point exposures indoors (due to cooking) that push the nonlinear model into a region of lower slopes.

Figure 2 illustrates the variability and uncertainty in median average effect factor estimates for $\mathrm{PM}_{2.5}$ exposure in each of the 3448 considered cities. Of the 3618 cities initially considered, 170 were excluded from our analysis because their mean ambient annual $\mathrm{PM}_{2.5}$ concentration was below the theoretical minimum risk exposure level, yielding an effect factor that is either zero or almost infinite. The vertical axis in Figure 2 reflects the range of city-specific effect factor estimates, which vary from less than 10 to $1900 \mathrm{DALY} / \mathrm{kg} \mathrm{PM}_{2.5}$ inhaled. The horizontal axis shows the $z$-score, indicating how many standard deviations the median effect factor for a specific city is from the mean across cities, calculated as $z$-score $=(X-$ $\mu) / \sigma$, with $X$ being the median effect factor for a given city, $\mu$ the mean effect factor across cities, and $\sigma$ the standard deviation. The fact that the 3448 city-specific median effect factor estimates lie, approximately, on a straight line suggests that median average urban effect factor estimates are approximately log-normally distributed with a median of 133 $\mathrm{DALY} / \mathrm{kg} \mathrm{PM}{ }_{2.5}$ inhaled and a geometric standard deviation of 1.95 (summarized in the box plot on the right side of Figure 2).

To illustrate the dependence of effect factors on $\mathrm{PM}_{2.5}$ exposure concentration levels, we color coded the data shown in Figure 2. Blue data points correspond to cities with $\mathrm{PM}_{2.5}$ concentrations between 5.8 and $15 \mu \mathrm{g} / \mathrm{m}^{3}$, yellow data points correspond to cities with $\mathrm{PM}_{2.5}$ concentrations between 15 and $25 \mu \mathrm{g} / \mathrm{m}^{3}$, and red data points correspond to cities with $\mathrm{PM}_{2.5}$ concentrations above $25 \mu \mathrm{g} / \mathrm{m}^{3}$. Finally, gray data points indicate cities with mean $\mathrm{PM}_{2.5}$ concentrations at or below the upper confidence interval limit of the theoretical minimum risk exposure level of $5.8 \mu \mathrm{g} / \mathrm{m}^{3}$. Increasing $\mathrm{PM}_{2.5}$ exposure concentrations yield lower effect factors for both cities and regions. This reflects the influence of the underlying nonlinear exposure-response model, suggesting modest reductions in 

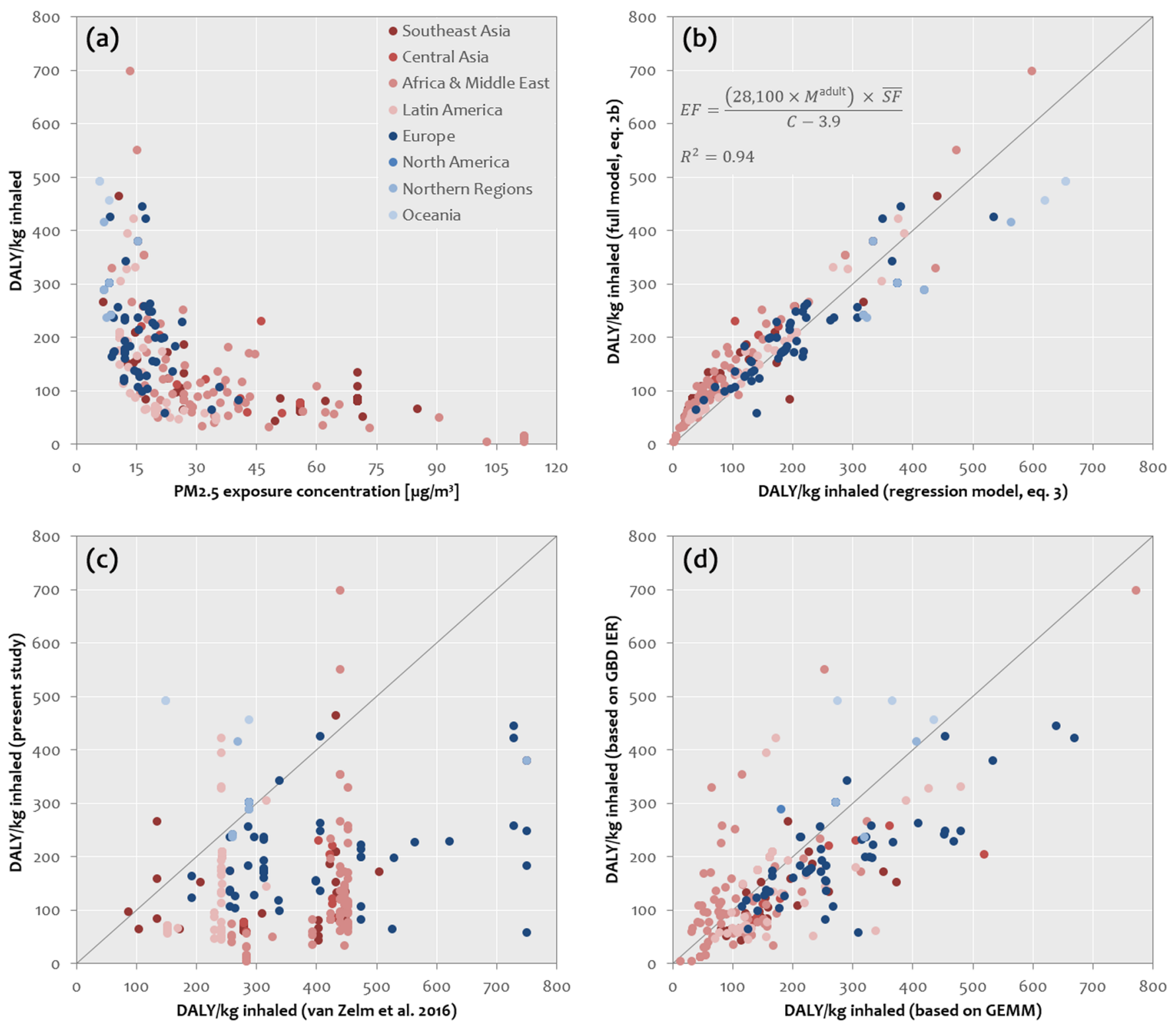

Figure 4. Effect factors estimated in the present study derived from the GBD IER (Integrated Exposure-Response) model ${ }^{36}$ for 419 regions compared against (a) their respective $\mathrm{PM}_{2.5}$ exposure levels, (b) our simplified regression model, (c) effect factors provided by van Zelm et al. $(2016),{ }^{24}$ and (d) effect factors derived from the Global Exposure Mortality Model (GEMM) ${ }^{48}$ Regression coefficients in (b) are for effect factors $\left(E F, D A L Y / k g\right.$ inhaled) in regions (including urban and rural areas). $M^{\text {adult }}$ (deaths/person-year), $\overline{S F}$ (DALY/death), and $C\left(\mu \mathrm{g} / \mathrm{m}^{3}\right)$, respectively, denote total adult mortality (considering IHD, stroke, COPD, and lung cancer, for age groups $\geq 25$ years), average severity factor over all age groups for the same diseases, and annual average $\mathrm{PM}_{2.5}$ exposure concentration per region. Plotted effect factor ranges are restricted to $800 \mathrm{DALY} /$ $\mathrm{kg}$ inhaled.

health burden in highly polluted areas unless $\mathrm{PM}_{2.5}$ levels markedly decline. ${ }^{36}$

Uncertainty in each of our effect factor estimates is reflected in the error bars shown for each city- and region-specific value. Because the GBD's IER model is highly nonlinear with a slope that approaches infinity as $\mathrm{PM}_{2.5}$ concentration levels approach the theoretical minimum risk exposure levels (which are themselves uncertain), effect factors become increasingly uncertain at levels of $\mathrm{PM}_{2.5}$ near this exposure level, usually reaching magnitudes beyond $500 \mathrm{DALY} / \mathrm{kg}$ inhaled. For comparison, effect factors based on GEMM (see Figure 2) generally deviate from results based on GBD's IER within a factor of 2 but also suggest a less extreme trend at both ends of the $\mathrm{PM}_{2.5}$ concentration range. In fact, very high effect factors are rather an artifact in the underlying exposure-response driven by studies on active smokers rather than ambient $\mathrm{PM}_{2.5}$ exposure, while very low effect factors are an artifact for forcing the curve to meet the minimum risk exposure level.

To relate effect factors in cities to those of their respective regions, we plot in Figure 3 the relationship of average effect factors between the various cities in each of the 175 considered countries (subnational regions were aggregated to national estimates) and the average slope effect factor for the respective country (considering all rural and urban areas in that country). Only 147 out of the 175 considered countries contain cities with more than 100000 inhabitants. For these countries, the number of cities ranges from a single city in, e.g., Iceland to 337 cities in India and 827 cities in China. In several countries, 
city-specific effect factors vary considerably, indicating that it is important to distinguish urban and rural factors and individual cities whenever related emission information is available. Cityspecific effect factors being higher than the related country averages across cities indicates that the overall country average is driven by (usually large) cities with higher $\mathrm{PM}_{2.5}$ levels and related lower effect factors.

3.2. Determinants of Effect Factors: Simplified Regression. In an effort to understand the determinants of effect factors related to $\mathrm{PM}_{2.5}$ exposure, we analyzed our results statistically. We found that for urban areas, marginal and average effect factors are well approximated with simple regression models of the following form:

$$
E F=\frac{\left(k_{1}+k_{2} \times M^{\text {adult }}\right) \times \overline{S F}}{C-k_{3}}
$$

where $M^{\text {adult }}$ is the total adult mortality rate (deaths/personyear) from the four related diseases considered by GBD's IER model for age groups $\geq 25$ years (derived from the ratio of the sum over age group specific deaths/year and population count), $\overline{S F}$ is the average severity factor (over all age groups) for the same four diseases, $C$ is the annual average ambient $\mathrm{PM}_{2.5}$ exposure concentration $\left(\mu \mathrm{g} / \mathrm{m}^{3}\right)$ in the area of interest, and $k_{1}, k_{2}$, and $k_{3}$ are fitting parameters.

First, we compared effect factors with their respective $\mathrm{PM}_{2.5}$ exposure levels (Figure $4 \mathrm{a}$ ). Using $1 / \mathrm{C}$ as the regression model explained $18 \%$ of the variance when taking average slope effect factors across our 419 considered regions. In a second model for the same data set, we estimated effect factors from $1 /(C-$ $\left.k_{3}\right)$, which explained $22 \%$ of the effect factors variance. Including mortality into the regression of the form $\left(k_{2} \times\right.$ $\left.M^{\text {adult }}\right) /\left(C-k_{3}\right)$ already explained $77 \%$ of our effect factor variance. Finally, we introduced severity factors into the model, which then takes the form as in eq 3, and explains $94 \%$ of the variance of average slope effect factors across regions as shown in Figure $4 b$.

For the 419 regions in our analysis, optimal values of model parameters for marginal slope effect factors, $E F_{\text {region }}^{\text {marginal }}$, are $k_{1}=$ 8 deaths/person-year, $k_{2}=15028$, and $k_{3}=0 \mu \mathrm{g} / \mathrm{m}^{3}$, yielding $R^{2}=0.95$. For average slope effect factors, $E F_{\text {region }}^{\text {avere }}$, in the 419 regions, the optimal parameter values are $k_{1}=0$ deaths/ person-year, $k_{2}=28100$, and $k_{3}=3.9 \mu \mathrm{g} / \mathrm{m}^{3}$, yielding $R^{2}=$ 0.94. It can be shown that for an average slope effect factor, the constant $k_{2}$ is an estimate of the average adjusted relative risk value of $10^{9} \frac{\mu \mathrm{g}}{\mathrm{kg}} \times[(R R(C)-1) / R R(C)] /\left(B R \times 365 \frac{\mathrm{d}}{\text { year }}\right)$. With the value of the nominal per-capita daily breathing rate of $11.68 \mathrm{~m}^{3} /$ person/d used in our analysis, an estimate of $k_{2}$ of 28100 is consistent with an average attributable risk fraction of 0.12 , corresponding to a relative risk of $R R=1.136$. The constant $k_{3}$ of $3.9 \mu \mathrm{g} / \mathrm{m}^{3}$ is an estimate of the theoretical minimum risk exposure level of $\mathrm{PM}_{2.5}$.

For the 3448 cities considered in our analysis, the optimal values of model parameters for marginal slope effect factors, $E F_{\text {city }}^{\text {marginal }}$, are $k_{1}=11$ deaths $/$ person-year, $k_{2}=13800$, and $k_{3}=$ $0.3 \mu \mathrm{g} / \mathrm{m}^{3}$, giving $R^{2}=0.96$. For average slope effect factors in cities, $E F_{\text {city }}^{\text {avere }}$, the optimal parameter values are $k_{1}=11$ deaths/person-year; $k_{2}=36311$, and $k_{3}=1.7 \mu \mathrm{g} / \mathrm{m}^{3}$, giving $R^{2}$ $=0.89$. It can be shown that for a marginal slope effect factor the constant $k_{2}$ is again an estimate of the average adjusted relative risk value, which is consistent with an average attributable risk fraction of 0.154 , corresponding to a relative risk of $R R=1.182$. The constant $k_{3}$ of $1.7 \mu \mathrm{g} / \mathrm{m}^{3}$ is again an estimate of the theoretical minimum risk exposure level of $\mathrm{PM}_{2.5}$. Overall, our simplified regression model predicts effect factors very well, using only information on $\mathrm{PM}_{2.5}$ exposure concentration, total adult mortality, and severity for any given region or city, which is readily available from the GBD study and global $\mathrm{PM}_{2.5}$ monitoring data.

\section{DISCUSSION}

4.1. Applicability of Our Effect Factors. We proposed a consistent set of global effect factors that can be combined with human intake fractions ${ }^{39}$ in support of comparative assessments that are relevant to a broad range of emission and related exposure situations, applicable to a diverse number of populations, cities, and countries, and applicable for different levels of spatial aggregation. While we can currently not differentiate between anthropogenic and nonanthropogenic $\mathrm{PM}_{2.5}$ sources (i.e., our approach is equally applicable to both), future efforts should focus on providing effect factors that are differentiated by source type. We found that estimating $\mathrm{PM}_{2.5}$ effect factors requires information for five underlying aspects, namely, (i) shape and parameters of the epidemiology-based exposure-response function, (ii) levels of $\mathrm{PM}_{2.5}$ exposure in the considered population, (iii) mortality rates for $\mathrm{PM}_{2.5}$ exposure-related diseases, (iv) severity factors reflecting loss of life expectancy and duration and severity of disease-related disability preceding death, and (v) amount of air inhaled by the exposed population. Of these, the most critical and uncertain information is that related to the exposure-response function. Comparing 4.2 with 8.9 million deaths globally estimated for 2015 using, respectively, GBD's IER model ${ }^{36}$ and the GEMM $^{48}$ (using all cohorts) indicates uncertainty of the exposure-response of at least a factor of 2 . This is dominating as compared to other contributors to uncertainty (breathing rates, exposure concentrations, and indoor/outdoor time patterns), which generally vary much less than a factor of $2^{41,44}$ In the mid-1990s, evidence about the exposureresponse relating chronic exposure to mortality was limited to the results from two cohort studies-the Six Cities study ${ }^{2}$ and the ACS study ${ }^{3}$ - these gave central effect estimates, which differed by a factor of 3 . More than 20 years later, results from a dozen relatively large cohort studies and an equal number of smaller cohorts contribute to our understanding of this issue.

A number of effect factor estimates for $\mathrm{PM}_{2.5}$ exposure has been proposed. All estimates have relied, almost exclusively, on evidence from one cohort, i.e., the ACS study ${ }^{3}$ (and its extensions and reanalyses). Although it is one of the largest and best-studied cohorts and used by regulatory authorities in the United States and Europe, we identified concerns about the ACS study. In particular, because of its use of ambient air exposures and health data for the United States, it may be unable to provide the best possible synthesis of evidence on mortality effects of chronic exposure to $\mathrm{PM}_{2.5}$ for use in the development of globally applicable effect factors.

The IER model provides an alternative synthesis, ${ }^{32}$ has been used to support estimates of the Global Burden of Disease since 2010, and has provided the basis for a number of independent studies of the mortality impacts of chronic exposure to ambient $\mathrm{PM}_{2.5}{ }^{1,29,30,33-36}$ GBD's IER model relies on evidence from all major cohort studies of mortality related to chronic exposure to $\mathrm{PM}_{2.5}$ and supplements this with information from studies of mortality impacts from exposure to smoke in households, which rely on dirty fuels for indoor 
cooking and heating, and from studies of exposure to both active and passive cigarette smoke. Using this model in our approach to develop global effect factors constitutes a more consistent picture than relying on evidence from a single region, thereby accounting for spatial variability in important underlying aspects including $\mathrm{PM}_{2.5}$ exposure levels, mortality, and disease severity.

4.2. Evaluation against Other Factors and Models. We explored the implications of using the synthesis provided by GBD's IER model for deriving effect factors and observed the following. First, our central estimates of global populationweighted marginal region and city effect factors are 44 and 54 DALY $/ \mathrm{kg} \mathrm{PM}_{2.5}$ inhaled, respectively. The variability in marginal slope effect factors across regions is substantial. If the location of a $\mathrm{PM}_{2.5}$ emissions source is unknown, the marginal slope effect factor could be between 17 and 127 (with 95\% confidence). Similar variability is found for emissions across cities. Second, our central estimates of the global population-weighted average slope region and city effect factors are 2-3 times as large as the corresponding marginal slope effect factors. The variability in average slope effect factors is also substantial. If the location of an emissions source is unknown, the average slope effect factor could be between 49 and 355 (with $95 \%$ confidence). Similar variability is again found across cities. We recommend applying the average effect factors rather than the marginal effect factors in cases where substantial variations in background $\mathrm{PM}_{2.5}$ exposure concentrations are expected over the lifetime of a considered system under analysis. This is, for example, the case in China, where a substantial reduction in concentrations has been observed in recent years and are expected in the coming decade, or for analyzing indoor PM mitigation scenarios, for which cooking alternatives can strongly reduce PM exposure levels. Third, although effect factors tend to be somewhat higher for some continents (North America, Oceania, Northern Regions) than for others (Southeast Asia, Central Asia, Latin America, Africa, and the Middle East), most of the variability in effect factors is within continent and is determined largely by variation in the average annual mean $\mathrm{PM}_{2.5}$ exposure concentrations from place to place. This occurs because of the nonlinearity of the IER exposure-response, which exhibits low slopes at high $\mathrm{PM}_{2.5}$ exposure concentrations and increasingly large slopes as $\mathrm{PM}_{2.5}$ exposure concentrations decrease toward the theoretical minimum risk exposure level of $\mathrm{PM}_{2.5}$. Fourth, our estimates of the population-weighted marginal and average slope effect factors for Europe are, respectively, $\sim 70$ and $\sim 150 \mathrm{DALY} / \mathrm{kg}$ $\mathrm{PM}_{2.5}$ inhaled and for North America, respectively, $\sim 110$ and $\sim 290 \mathrm{DALY} / \mathrm{kg} \mathrm{PM}_{2.5}$ inhaled. Differences between Europe and the United States are mainly driven by lower $\mathrm{PM}_{2.5}$ levels in the United States (leading to higher exposure-response slopes), and our estimates are only slightly larger than previous estimates of $58 \mathrm{YLL}$ per $\mathrm{kg} \mathrm{PM}_{2.5}$ inhaled (Europe) ${ }^{22}$ and 78 DALY per kg $\mathrm{PM}_{2.5}$ inhaled (United States). ${ }^{23}$ Fifth, similar to recent studies, ${ }^{24,25}$ we provide estimates of effect factors appropriate for various countries and regions worldwide. Our estimates of population-weighted marginal slope effect factors are both variable and uncertain, with typical values varying from $27 \mathrm{DALY} / \mathrm{kg} \mathrm{PM}_{2.5}$ inhaled (95\% confidence interval, 17-120) in Central Asia to $168 \mathrm{DALY} / \mathrm{kg} \mathrm{PM}_{2.5}$ inhaled (95\% confidence interval, 78-306) in Northern Regions. Previous estimates are also variable and uncertain, varying from 87 YLL/ $\mathrm{kg} \mathrm{PM}_{2.5}$ inhaled in Thailand to $857 \mathrm{YLL} / \mathrm{kg} \mathrm{PM}_{2.5}$ inhaled in Kazakhstan. ${ }^{24}$ However, as Figure $4 \mathrm{c}$ shows, the different sets of estimates present quite distinct pictures of both the patterns and sources of variability and the nature and extent of uncertainty in effect factor estimates. These differences are primarily due to the nonlinearity in GBD's IER model being the major source of variability in our estimates, a feature not present in earlier estimates. ${ }^{24,25}$

In conducting this analysis we are not proposing that effect factors based on GBD's IER model are more reliable than estimates based on other syntheses of the epidemiological evidence for mortality effects of $\mathrm{PM}_{2.5}$. Instead, the goal of our analysis is to illustrate the importance of the approach used to synthesize exposure-response evidence for compiling a globally consistent set of effect factors that allow for evaluating emission and emission reduction situations at different spatial levels. We note that uncertainty about how to synthesize epidemiological evidence is arguably the largest, often unacknowledged source of uncertainty in $\mathrm{PM}_{2.5}$ effect factor estimates. To evaluate this aspect, we finally developed effect factors following our general approach but using the recently published Global Exposure Mortality Model (GEMM) ${ }^{48}$ and compared results against our factors based on GBD's IER model (see Figure 2). Comparing both sets of effect factors for the 419 considered regions we find that GEMM-based factors overall agree well with IER-based factors (Figure 4d); however, there are some deviations especially at very high and very low $\mathrm{PM}_{2.5}$ exposure levels, where the GEMM is less nonlinear than the IER model. This suggests that the relative risk estimates underlying our analysis could be potentially limited at both extremes of the considered $\mathrm{PM}_{2.5}$ range to yield effect factors that are better aligned with GEMM and less influenced by artifacts related to the IER shape. An advantage of using GEMM as the underlying exposure-response model could be that each included cohort can be fitted separately for a given region. However, additional research is required to select, for example, the appropriate cohorts in GEMM for regions where no epidemiological evidence is currently available.

On the basis of the current state-of-the-science synthesis used by the GBD study, ${ }^{36}$ our effect factor estimates can be consistently coupled with the indoor and outdoor region and city-specific intake fractions ${ }^{39}$ for use in LCIA, comparative risk and health impact assessments, and emission reduction policy analyses. Our continental, country- and region-level, and city-specific effect factors thereby capture important variability in mortality from exposure to $\mathrm{PM}_{2.5}$, which is not possible with currently available spatialized models. As science advances and new syntheses of the epidemiological evidence on mortality attributable to $\mathrm{PM}_{2.5}$ exposure becomes available, our approach can easily accommodate this new information to produce updated global effect factors for exposure to $\mathrm{PM}_{2.5}$.

4.3. Recommendations for Policy and Practitioners. Effect factors for exposure to $\mathrm{PM}_{2.5}$ combined with intake fractions ${ }^{39}$ provide important insight when evaluating different emission and emission reduction situations. Effect factors vary considerably across cities and regions (Figures 1 and 3), with lower effect factors in areas with higher $\mathrm{PM}_{2.5}$ exposure and highest effect factors in areas with $\mathrm{PM}_{2.5}$ exposure close to the minimum risk exposure level (Figures 2 and $4 \mathrm{a}$ ). Current spatial models are unable to capture the most important related variabilities in effect factors (see Figure 4c). Our consistent set of global effect factors addresses this spatial variability by covering different spatial scales through parametrized cities and countries (or subnational regions), continents, and global averages that can be applied as a 
function of information available about emission location. We recommend using as underlying exposure-response model GBD's IER covering a wide range of $\mathrm{PM}_{2.5}$ exposure concentrations based on a large set of epidemiological studies from different regions ${ }^{36}$ while further exploring other models, such as GEMM. ${ }^{48}$ GEMM is generally in good agreement with the IER but also exhibits important differences, such as a more linear behavior at high $\mathrm{PM}_{2.5}$ exposures (see Figure $4 \mathrm{~d}$ ). However, important questions still need to be addressed before GEMM can be applied in a global context, for example, selection of appropriate cohorts in areas without available epidemiological evidence. We generally recommend applying effect factors derived from an average slope, where substantial variations in background $\mathrm{PM}_{2.5}$ exposure are expected over the lifetime of an assessed product system or as consequence of emission or exposure reduction efforts. Finally, when only limited information is available regarding $\mathrm{PM}_{2.5}$ exposure, mortality, and disease severity, we recommend applying our simplified regression model (eq 3, Figure 4b) with different fitting coefficients for regions, cities, and marginal versus average slopes. Further research should focus on providing globally spatialized data on time spent indoors/outdoors, breathing rates, additional health outcomes associated with $\mathrm{PM}_{2.5}$ exposure, epidemiological evidence in regions currently not covered, and effect factors differentiated by source type.

\section{ASSOCIATED CONTENT}

\section{S Supporting Information}

The Supporting Information is available free of charge on the ACS Publications website at DOI: 10.1021/acs.est.9b01800.

Operational $\mathrm{PM}_{2.5}$ effect factor model and all numerical effect factor results (XLSX)

\section{AUTHOR INFORMATION}

\section{Corresponding Author}

*Phone: +45 45254452; fax: +45 45933435; e-mail: pefan@ dtu.dk.

\section{ORCID}

Peter Fantke: 0000-0001-7148-6982

Olivier Jolliet: 0000-0001-6955-4210

Joshua S. Apte: 0000-0002-2796-3478

\section{Notes}

The authors declare no competing financial interest.

\section{ACKNOWLEDGMENTS}

This work was supported by the Life Cycle Initiative hosted at the UN Environment and by the Centre for Diet and Activity Research (CEDAR), a UKCRC Public Health Research Centre of Excellence. Funding from the British Heart Foundation, Cancer Research UK, Economic and Social Research Council, Medical Research Council, the National Institute for Health Research, and the Wellcome Trust, under the auspices of the UK Clinical Research Collaboration, is gratefully acknowledged. The work was developed in part under Assistance Agreement No. R835873 awarded by the US Environmental Protection Agency. The views expressed in this document are those of the authors.

\section{REFERENCES}

(1) Forouzanfar, M. H.; et al. GBD 2015 Risk Factors Collaborators, Global, regional, and national comparative risk assessment of 79 behavioural, environmental and occupational, and metabolic risks or clusters of risks, 1990-2015: A systematic analysis for the Global Burden of Disease Study 2015. Lancet 2016, 388, 1659-1724.

(2) Dockery, D. W.; Pope, C. A.; Xu, X.; Spengler, J. D.; Ware, J. H.; Fay, M. E.; Ferris, B. G.; Speizer, F. E. An association between air pollution and mortality in six U.S. cities. N. Engl. J. Med. 1993, 329, 1753-1759.

(3) Pope, C. A., III; Thun, M. J.; Namboodiri, M. M.; Dockery, D. W.; Evans, J. S.; Speizer, F. E.; Heath, C. W. Particulate air pollution as a predictor of mortality in a prospective study of U.S. adults. Am. J. Respir. Crit. Care Med. 1995, 151, 669-674.

(4) Hofstetter, P. Perspectives in Life Cycle Impact Assessment: A Structured Approach to Combine Models of the Technosphere, Ecosphere and Valuesphere; Kluwer Academic Publishers: Boston, MA, 1998.

(5) Bennett, D. H.; McKone, T. E.; Evans, J. S.; Nazaroff, W. W.; Margni, M. D.; Jolliet, O.; Smith, K. R. Defining intake fraction. Environ. Sci. Technol. 2002, 36, 206A-211A.

(6) Humbert, S.; Marshall, J. D.; Shaked, S.; Spadaro, J. V.; Nishioka, Y.; Preiss, P.; McKone, T. E.; Horvath, A.; Jolliet, O. Intake fraction for particulate matter: Recommendations for life cycle impact assessment. Environ. Sci. Technol. 2011, 45, 4808-4816.

(7) Fantke, P.; Jolliet, O.; Apte, J. S.; Cohen, A. J.; Evans, J. S.; Hänninen, O. O.; Hurley, F.; Jantunen, M. J.; Jerrett, M.; Levy, J. I.; Loh, M. M.; Marshall, J. D.; Miller, B. G.; Preiss, P.; Spadaro, J. V.; Tainio, M.; Tuomisto, J. T.; Weschler, C. J.; McKone, T. E. Health effects of fine particulate matter in life cycle impact assessment: Conclusions from the Basel guidance workshop. Int. J. Life Cycle Assess. 2015, 20, 276-288.

(8) Pope, C. A., III; Burnett, R. T.; Thun, M. J.; Calle, E. E.; Krewski, D.; Ito, K.; Thurston, G. D. Lung cancer, cardiopulmonary mortality, and long-term exposure to fine particulate air pollution. J. Am. Med. Assoc. 2002, 287, 1132-1141.

(9) Krewski, D.; Jerrett, M.; Burnett, R. T.; Ma, R.; Hughes, E.; Shi, Y.; Turner, M. C.; Pope, C. A., III; Thurston, G.; Calle, E. E.; Thun, M. J. Extended Follow-Up and Spatial Analysis of the American Cancer Society Study Linking Particulate Air Pollution and Mortality. HEI Research Report 140; HEI: Boston, MA, 2009.

(10) Laden, F.; Schwartz, J.; Speizer, F. E.; Dockery, D. W. Reduction in fine particulate air pollution and mortality. Am. J. Respir. Crit. Care Med. 2006, 173, 667-672.

(11) Lepeule, J.; Laden, F.; Dockery, D.; Schwartz, J. Chronic exposure to fine particles and mortality: An extended follow-up of the Harvard Six Cities study from 1974 to 2009. Environ. Health Perspect. 2012, 120, 965-970.

(12) Ostro, B.; Lipsett, M.; Reynolds, P.; Goldberg, D.; Hertz, A.; Garcia, C.; Henderson, K. D.; Bernstein, L. Long-term exposure to constituents of fine particulate air pollution and mortality: Results from the California Teachers Study. Environ. Health Perspect. 2010, 118, 363-369.

(13) Puett, R. C.; Schwartz, J.; Hart, J. E.; Yanosky, J. D.; Speizer, F. E.; Suh, H.; Paciorek, C. J.; Neas, L. M.; Laden, F. Chronic particulate exposure, mortality, and coronary heart disease in the Nurses' Health Study. Am. J. Epidemiol. 2008, 168, 1161-1168.

(14) Beelen, R.; Hoek, G.; van den Brandt, P. A.; Goldbohm, R. A.; Fischer, P.; Schouten, L. J.; Jerrett, M.; Hughes, E.; Armstrong, B.; Brunekreef, B. Long-term effects of traffic-related air pollution on mortality in a Dutch cohort (NLCS-AIR study). Environ. Health Perspect. 2008, 116, 196-202.

(15) Abbey, D. E.; Nishino, N.; McDonnell, W. F.; Burchette, R. J.; Knutsen, S. F.; Beeson, W. L.; Yang, J. X. Long-term inhalable particles and other air pollutants related to mortality in nonsmokers. Am. J. Respir. Crit. Care Med. 1999, 159, 373-382.

(16) Miller, K. A.; Siscovick, D. S.; Sheppard, L.; Shepherd, K.; Sullivan, J. H.; Anderson, G. L.; Kaufman, J. D. Long-term exposure to air pollution and incidence of cardiovascular events in women. $N$. Engl. J. Med. 2007, 356, 447-458.

(17) Puett, R. C.; Hart, J. E.; Suh, H.; Mittleman, M.; Laden, F. Particulate matter exposures, mortality, and cardiovascular disease in 
the Health Professionals Follow-up Study. Environ. Health Perspect. 2011, 119, 1130-1135.

(18) Cesaroni, G.; Badaloni, C.; Gariazzo, C.; Stafoggia, M.; Sozzi, R.; Davoli, M.; Forastiere, F. Long-term exposure to urban air pollution and mortality in a cohort of more than a million adults in Rome. Environ. Health Perspect. 2013, 121, 324-331.

(19) Zeger, S. L.; Dominici, F.; McDermott, A.; Samet, J. M. Mortality in the medicare population and chronic exposure to fine particulate air pollution in urban centers (2000-2005). Environ. Health Perspect. 2008, 116, 1614-1619.

(20) Beelen, R.; Raaschou-Nielsen, O.; Stafoggia, M.; Andersen, Z. J.; Weinmayr, G.; Hoffmann, B.; Wolf, K.; Samoli, E.; Fischer, P.; Nieuwenhuijsen, M.; Vineis, P.; Xun, W. W.; Katsouyanni, K.; Dimakopoulou, K.; Oudin, A.; Forsberg, B.; Modig, L.; Havulinna, A. S.; Lanki, T.; Turunen, A.; Oftedal, B.; Nystad, W.; Nafstad, P.; De Faire, U.; Pedersen, N. L.; Östenson, C.-G.; Fratiglioni, L.; Penell, J.; Korek, M.; Pershagen, G.; Eriksen, K. T.; Overvad, K.; Ellermann, T.; Eeftens, M.; Peeters, P. H.; Meliefste, K.; Wang, M.; Bueno-deMesquita, B.; Sugiri, D.; Krämer, U.; Heinrich, J.; de Hoogh, K.; Key, T.; Peters, A.; Hampel, R.; Concin, H.; Nagel, G.; Ineichen, A.; Schaffner, E.; Probst-Hensch, N.; Künzli, N.; Schindler, C.; Schikowski, T.; Adam, M.; Phuleria, H.; Vilier, A.; Clavel-Chapelon, F.; Declercq, C.; Grioni, S.; Krogh, V.; Tsai, M.-Y.; Ricceri, F.; Sacerdote, C.; Galassi, C.; Migliore, E.; Ranzi, A.; Cesaroni, G.; Badaloni, C.; Forastiere, F.; Tamayo, I.; Amiano, P.; Dorronsoro, M.; Katsoulis, M.; Trichopoulou, A.; Brunekreef, B.; Hoek, G. Effects of long-term exposure to air pollution on natural-cause mortality: An analysis of 22 European cohorts within the multicentre ESCAPE project. Lancet 2014, 383, 785-795.

(21) Hoek, G.; Krishnan, R. M.; Beelen, R.; Peters, A.; Ostro, B.; Brunekreef, B.; Kaufman, J. D. Long-term air pollution exposure and cardio-respiratory mortality: A review. Environ. Health 2013, 12, 4357.

(22) van Zelm, R.; Huijbregts, M. A. J.; den Hollander, H. A.; van Jaarsveld, H. A.; Sauter, F. J.; Struijs, J.; van Wijnen, H. J.; van de Meent, D. European characterization factors for human health damage of $\mathrm{PM}_{10}$ and ozone in life cycle impact assessment. Atmos. Environ. 2008, 42, 441-453.

(23) Gronlund, C. J.; Humbert, S.; Shaked, S.; O’Neill, M. S.; Jolliet, $\mathrm{O}$. Characterizing the burden of disease of particulate matter for life cycle impact assessment. Air Qual., Atmos. Health 2015, 8, 29-46.

(24) van Zelm, R.; Preiss, P.; van Goethem, T.; Van Dingenen, R.; Huijbregts, M. Regionalized life cycle impact assessment of air pollution on the global scale: Damage to human health and vegetation. Atmos. Environ. 2016, 134, 129-137.

(25) Tang, L.; Nagashima, T.; Hasegawa, K.; Ohara, T.; Sudo, K.; Itsubo, N. Development of human health damage factors for $\mathrm{PM}_{2.5}$ based on a global chemical transport model. Int. J. Life Cycle Assess. 2018, 23, 2300-2310.

(26) Künzli, N.; Kaiser, R.; Medina, S.; Studnicka, M.; Chanel, O.; Filliger, P.; Herry, M.; Horak, F.; Puybonnieux-Texier, V.; Quénel, P.; Schneider, J.; Seethaler, R.; Vergnaud, J.-C.; Sommer, H. Publichealth impact of outdoor and traffic-related air pollution: A European assessment. Lancet 2000, 356, 795-801.

(27) Global Modelled Ambient Air Pollution: Annual mean $P_{2.5}$ levels estimated with the Data Integration Model for Air Quality (DIMAQ); World Health Organization, 2016; http://www.who.int/airpollution/ data/modelled-estimates (accessed Jan 19, 2018).

(28) Levy, J. I.; Diez, D.; Dou, Y.; Barr, C. D.; Dominici, F. A metaanalysis and multisite time-series analysis of the differential toxicity of major fine particulate matter constituents. Am. J. Epidemiol. 2012, 175, 1091-1099.

(29) Lim, S. S. GBD 2010 Risk Factors Collaborators, A comparative risk assessment of burden of disease and injury attributable to 67 risk factors and risk factor clusters in 21 regions, 1990-2010: A systematic analysis for the Global Burden of Disease Study 2010. Lancet 2012, 380, 2224-2260.

(30) Forouzanfar, M. M. GBD 2013 Risk Factors Collaborators, Global, regional, and national comparative risk assessment of 79 behavioural, environmental and occupational, and metabolic risks or clusters of risks in 188 countries, 1990-2013: A systematic analysis for the Global Burden of Disease Study 2013. Lancet 2015, 386, $2287-2323$.

(31) Stanaway, J. D. GBD 2017 Risk Factor Collaborators, Global, regional, and national comparative risk assessment of 84 behavioural, environmental and occupational, and metabolic risks or clusters of risks for 195 countries and territories, 1990-2017: A systematic analysis for the Global Burden of Disease Study 2017. Lancet 2018, 392, 1923-1994.

(32) Burnett, R. T.; Pope, C. A., III; Ezzati, M.; Olives, C.; Lim, S. S.; Mehta, S.; Shin, H. H.; Singh, G.; Hubbell, B.; Brauer, M.; Anderson, H. R.; Smith, K. R.; Balmes, J. R.; Bruce, N. G.; Kan, H.; Laden, F.; Prüss-Ustün, A.; Turner, M. C.; Gapstur, S. M.; Diver, W. R.; Cohen, A. An integrated risk function for estimating the global burden of disease attributable to ambient fine particulate matter exposure. Environ. Health Perspect. 2014, 122, 397-403.

(33) Nasari, M. M.; Szyszkowicz, M.; Chen, H.; Crouse, D.; Turner, M. C.; Jerrett, M.; Pope, C. A.; Hubbell, B.; Fann, N.; Cohen, A.; Gapstur, S. M.; Diver, W. R.; Stieb, D.; Forouzanfar, M. H.; Kim, S.Y.; Olives, C.; Krewski, D.; Burnett, R. T. A class of non-linear exposure-response models suitable for health impact assessment applicable to large cohort studies of ambient air pollution. Air Qual., Atmos. Health 2016, 9, 961-972.

(34) Apte, J. S.; Marshall, J. D.; Cohen, A. J.; Brauer, M. Addressing global mortality from ambient $\mathrm{PM}_{2.5}$. Environ. Sci. Technol. 2015, 49, 8057-8066.

(35) Lelieveld, J.; Evans, J. S.; Fnais, M.; Giannadaki, D.; Pozzer, A. The contribution of outdoor air pollution sources to premature mortality on a global scale. Nature 2015, 525, 367-371.

(36) Cohen, A. J.; Brauer, M.; Burnett, R.; Anderson, H. R.; Frostad, J.; Estep, K.; Balakrishnan, K.; Brunekreef, B.; Dandona, L.; Dandona, R.; Feigin, V.; Freedman, G.; Hubbell, B.; Jobling, A.; Kan, H.; Knibbs, L.; Liu, Y.; Martin, R.; Morawska, L.; Pope, C. A., III; Shin, H.; Straif, K.; Shaddick, G.; Thomas, M.; van Dingenen, R.; van Donkelaar, A.; Vos, T.; Murray, C. J. L.; Forouzanfar, M. H. Estimates and 25-year trends of the global burden of disease attributable to ambient air pollution: An analysis of data from the Global Burden of Diseases Study 2015. Lancet 2017, 389, 1907-1918.

(37) Frischknecht, R.; Fantke, P.; Tschümperlin, L.; Niero, M.; Antón, A.; Bare, J.; Boulay, A.-M.; Cherubini, F.; Hauschild, M. Z.; Henderson, A.; Levasseur, A.; McKone, T. E.; Michelsen, O.; Mila y Canals, L.; Pfister, S.; Ridoutt, B.; Rosenbaum, R. K.; Verones, F.; Vigon, B.; Jolliet, O. Global guidance on environmental life cycle impact assessment indicators: Progress and case study. Int. J. Life Cycle Assess. 2016, 21, 429-442.

(38) Jolliet, O.; Antón, A.; Boulay, A.-M.; Cherubini, F.; Fantke, P.; Levasseur, A.; McKone, T. E.; Michelsen, O.; Milà i Canals, L.; Motoshita, M.; Pfister, S.; Verones, F.; Vigon, B.; Frischknecht, R. Global guidance on environmental life cycle impact assessment indicators: Impacts of climate change, fine particulate matter formation, water consumption and land use. Int. J. Life Cycle Assess. 2018, 23, 2189-2207.

(39) Fantke, P.; Jolliet, O.; Apte, J. S.; Hodas, N.; Evans, J.; Weschler, C. J.; Stylianou, K. S.; Jantunen, M.; McKone, T. E. Characterizing aggregated exposure to primary particulate matter: Recommended intake fractions for indoor and outdoor sources. Environ. Sci. Technol. 2017, 51, 9089-9100.

(40) Kounina, A.; Margni, M.; Shaked, S.; Bulle, C.; Jolliet, O. Spatial analysis of toxic emissions in LCA: A sub-continental nested USEtox model with freshwater archetypes. Environ. Int. 2014, 69, 6789.

(41) Apte, J. S.; Bombrun, E.; Marshall, J. D.; Nazaroff, W. W. Global intraurban intake fractions for primary air pollutants from vehicles and other distributed sources. Environ. Sci. Technol. 2012, 46, $3415-3423$

(42) Shaddick, G.; Thomas, M. L.; Jobling, A.; Brauer, M.; van Donkelaar, A.; Burnett, R.; Chang, H.; Cohen, A.; Van Dingenen, R.; Dora, C.; Gumy, S.; Liu, Y.; Martin, R.; Waller, L. A.; West, J.; Zidek, 
J. V.; Prüss-Ustün, A. Data integration model for air quality: A hierarchical approach to the global estimation of exposures to ambient air pollution. arXiv 2016, 1609, 00141.

(43) Smith, K. R.; Bruce, N.; Balakrishnan, K.; Adair-Rohani, H.; Balmes, J.; Chafe, Z.; Dherani, M.; Hosgood, H. D.; Mehta, S.; Pope, D.; Rehfuess, E. Millions dead: How do we know and what does it mean? Methods used in the comparative risk assessment of household air pollution. Annu. Rev. Public Health 2014, 35, 185-206.

(44) Hodas, N.; Loh, M.; Shin, H.-M.; Li, D.; Bennett, D.; McKone, T. E.; Jolliet, O.; Weschler, C. J.; Jantunen, M.; Lioy, P.; Fantke, P. Indoor inhalation intake fractions of fine particulate matter: Review of influencing factors. Indoor Air 2016, 26, 836-856.

(45) Global Burden of Disease Study 2016 (GBD 2016) Results; GBD Global Burden of Disease Collaborative Network, 2018; http://ghdx. healthdata.org/gbd-results-tool (accessed Sep 16, 2018).

(46) Wang, H. GBD 2016 Mortality Collaborators, Global, regional, and national under-5 mortality, adult mortality, age-specific mortality, and life expectancy, 1970-2016: A systematic analysis for the Global Burden of Disease Study 2016. Lancet 2017, 390, 1084-1150.

(47) Nazaroff, W. W.; Goldstein, A. H. Indoor chemistry: Research opportunities and challenges. Indoor Air 2015, 25, 357-361.

(48) Burnett, R.; Chen, H.; Szyszkowicz, M.; Fann, N.; Hubbell, B.; Pope, C. A.; Apte, J. S.; Brauer, M.; Cohen, A.; Weichenthal, S.; Coggins, J.; Di, Q.; Brunekreef, B.; Frostad, J.; Lim, S. S.; Kan, H.; Walker, K. D.; Thurston, G. D.; Hayes, R. B.; Lim, C. C.; Turner, M. C.; Jerrett, M.; Krewski, D.; Gapstur, S. M.; Diver, W. R.; Ostro, B.; Goldberg, D.; Crouse, D. L.; Martin, R. V.; Peters, P.; Pinault, L.; Tjepkema, M.; van Donkelaar, A.; Villeneuve, P. J.; Miller, A. B.; Yin, P.; Zhou, M.; Wang, L.; Janssen, N. A. H.; Marra, M.; Atkinson, R. W.; Tsang, H.; Quoc Thach, T.; Cannon, J. B.; Allen, R. T.; Hart, J. E.; Laden, F.; Cesaroni, G.; Forastiere, F.; Weinmayr, G.; Jaensch, A.; Nagel, G.; Concin, H.; Spadaro, J. V. Global estimates of mortality associated with long-term exposure to outdoor fine particulate matter. Proc. Natl. Acad. Sci. U. S. A. 2018, 115, 9592-9597.

(49) Bruce, N.; Pope, D.; Rehfuess, E.; Balakrishnan, K.; AdairRohani, H.; Dora, C. WHO indoor air quality guidelines on household fuel combustion: Strategy implications of new evidence on interventions and exposure-risk functions. Atmos. Environ. 2015, $106,451-457$. 